\title{
Congenital Hydroureter
}

National Cancer Institute

\section{Source}

National Cancer Institute. Congenital Hydroureter. NCI Thesaurus. Code C103922.

Dilatation of the ureter caused by obstruction of urine flow that is present at birth. 